\title{
LETTERS
}

\section{Health Canada has cautioned against use of boric acid- containing products}

I read with interest the recent article by Kong and Lam on slime dermatitis. ${ }^{1}$ Physicians should be aware and inform patients that use of boric acid-containing products in children's crafts and homemade pesticides has been previously cautioned by Health Canada.

In 2016, Health Canada listed a specific advisory cautioning Canadians against the use of boric acid in homemade crafts and pesticides, especially for children and pregnant women, after a draft risk assessment which found that overexposure to boric acid has the potential to cause developmental and reproductive health effects. ${ }^{2}$
Further information from Health Canada regarding borax (boric acid, its salts and precursors) is available. ${ }^{3}$

Health Canada lists a variety of other products to avoid in children's arts and crafts supplies, including paint that is not clearly labelled as safe for kids, powdered clays and paint, ceramic glazes, copper enamel, solder for stained glass, shellac paint strippers and craft dyes, as well as boric acid. A full list and further information on using arts and crafts materials safely is available from Health Canada. $^{4}$

\section{Christopher Earle MD}

Psychiatry resident, Memorial University of Newfoundland, St. John's, NL
Cite as: CMAJ 2019 September 16;191: E1032. doi: $10.1503 / \mathrm{cmaj} .72750$

\section{References}

1. Kong C, Lam JM. Slime dermatitis. CMAJ 2019 191:E536.

2. Information update - Health Canada advises Canadians to avoid homemade craft and pesticide recipes using boric acid. Ottawa: Health Canada; modified 2016. Available: https://healthycanadians.gc. ca/recall-alert-rappel-avis/hc-sc/2016/59514a-eng. php (accessed 2019 May 13).

3. Boric acid. Ottawa: Health Canada; modified 2016. Available: www.canada.ca/en/health-canada/ services/chemicals-product-safety/boric-acid.html (accessed 2019 May 13).

4. Use arts and crafts materials safely. Ottawa: Health Canada; modified 2017. Available: www.canada.ca/ en/health-canada/services/home-garden-safety/use -arts-crafts-materials-safely.html (accessed 2019 May 13).

Competing interests: None declared. 